\title{
THE POLISH CURRENT OF CRITICISM OF GERMAN NATIONAL SOCIALISM (NAZISM) BEFORE 1939. BIBLIOGRAPHY OF SOURCES
}

Already at the end of the 1920s, in addition to the outstanding sovietological ${ }^{2}$ studies conducted by Poles, there was a criticism in Poland of the nascent total ideology of German national socialists, i.e. Nazis m (Nazism, as an ideology built on the combination of German nationalism with features specific only to the Germans and socialism, should not be generalised and referred to other nations than Germany of that era).

In Poland, the belief that Nazism was a threat to the peaceful development of Europe was born. Moreover, it became clear to Poles that preserving our national identity was tantamount to denying not only Soviet Bolshevism but also Nazism. In this situation, especially in Polish literature of conservative-national and Catholic orientation at the same time, a critical discourse against Nazism arose. Its most valuable aspect was that it took place before the Holocaust that is why it surpasses all Western criticism of Nazism after World War II in its ethical dimension. The paradox is the widespread lack of knowledge about its existence in the world and its absence on the forum of world discourse.

A certain scope of Polish criticism of Nazism is contained in the bibliography of sources presented below (not complete). It contains scientific and popular science works (in the case of the National Thought - journalistic): dissertations,

1 Prof. dr hab. Janina Kostkiewicz, head of the Department of High School Pedagogy and the Polish Pedagogical Thought in Institute of Pedagogy at the Faculty of Philosophy of the Jagiellonian University; editor-in-chief of this journal. Institute of Pedagogy UJ, ul. Batorego 12, 31-135 Kraków; e-mail: janina.kostkiewicz@uj.edu.pl.

2 See: Janina Kostkiewicz, "The Polish Current of Criticism of Communism (Bolshevism) in the Years 1917-1939. Bibliography of Sources”, Polska Myśl Pedagogiczna 6 (2020). 
articles, the author's and collective monographs, brochures and studies that criticise German National Socialism.

I collected the following bibliography as a result of a search of various Polish archival resources from 1918-1939. It includes magazines published in Kraków, Lviv, Vilnius, Warszawa, Poznań and other centres of Polish intellectual life. They include: Ateneum Kapłańskie (a monthly magazine of professors of the Włocławek Theological Seminary); Kultura i Wychowanie (until 1939 the Publisher was the General Board of the Society of Secondary and Higher Education Teachers); Kwartalnik Pedagogiczny (a magazine of the Pedagogical Section of the Association of Christian-National Teachers of Common Schools); Miesięcznik Katechetyczny i Wychowawczy (a letter from the Association of Diocesan Circles of Prefect Priests: Lviv-Warsaw); Muzeum (Lviv); Prad (a letter from the Association of Catholic Academic Youth "Odrodzenie"); Przeglad Powszechny (Jesuits Kraków); Przewodnik Społeczny (Poznań); Philosophical Yearbooks of the Catholic University of Lublin; Scientific Papers of the Catholic University of Lublin (KUL); Yearbooks of various dioceses; Ruch Katolicki (the body of the Catholic Action in Poland); Myśl Narodowa (a weekly magazine); Diaries from various conventions and congresses. The sources also include books, brochures and offprints from various publications.

An attempt to summarise ${ }^{3}$ the Polish current of criticism of Nazism before 1939 leads to the following picture. In the writings of the Polish humanists, German National Socialism (Nazism) was a socio-political movement, combining the features of socialism and nationalism; a mass movement, intended for the average mental level, broad, reaching in its means from monarchism to Bolshevism. It was characterised by racism, anti-democracy, the idea of Germanicism and materialism - which undermined elementary forms of humanitarianism. This criticism is dominated by the conviction that all nationalistic ideals in Germany come primarily from great philosophers (mainly Johan G. Fichte and George W.F. Hegel); that these thinkers "shaped the spirit and mentality of the German nation and pushed it on the paths of nationalism and politicalism": nationalism concerns the attitude of the individual to the nation, and politicism - the attitude of the individual to the state. Alongside Hegel's philosophy describing/creating the "spirit of the nation", the following are pointed out: Pan-Germanism, the idea of community, the instrumental use of religion transformed into a pseudo-religious religion and science "at the service" with the important role of eugenics. Nazism was served by new ideals and methods of upbringing with collective and

3 I am enclosing here a shortened version of a part of my chapter entitled "Polish Current of Criticism of Totalitarianisms" published in a collective work. See: Janina Kostkiewicz, "Polski nurt krytyki totalitaryzmów”, in: Pedagogika. Podręcznik akademicki, eds. Zbigniew Kwieciński, Bogusław Śliwerski (Warszawa: PWN, 2019), 167-176.

4 Paweł Tochowicz, "Zasady wychowawcze nacjonalizmu i politycyzmu”, Ateneum Kapłańskie 39 (1937), 153. 
leadership qualities - homogeneous in school and youth organisations and the media. National Socialism also created a new ethic proclaiming that the good is what benefits the State. An individual may act according to his own conscience in his own affairs, but when it comes to the affairs of the nation and the state, the voice of conscience should be suppressed ${ }^{5}$.

As far as the roots of Nazism are concerned, the question arises: what happened in Germany to the cosmopolitan environment of Frederick the Great in the $18^{\text {th }}$ century, which idolised French language and literature? What awakened the aggressive "Germanic spirit" and escalating the claim to world domination? One of the themes is the Napoleonic Wars and the defeat of Germany at the Battle of Jena in 1806 - this is where the idea of German domination in the world matures. It is claimed that the greatest role was played by Fichte, who in 1808 in Berlin announced the Addresses to the German Nation, which became the gospel of their nationalism. No philosopher has ever flattered a nation like him. Fichte created a theory of nationalism, in which the national character is revealed in the originality of the products of his spirit: language, literature, art, science, beliefs and economic life. Fichte's thesis that "language constitutes a nation" carried the message that the spirit of the nation that created such a language must be original; such a nation is a "super-nation". Fichte was thus recognised as the founder of cultural nationalism, and Hegel as the founder of the foundations of political nationalism". They were completed by: a) the grim idea of "Germany's destiny" to be a dominant nation, which was combined with an idea (taken from the Song of the Nibelungs) of a lack of understanding of its greatness ${ }^{7}$; b) visions of an idealistic philosophy constructing the world from selected ideas; c) political theses about the artificiality of division between Prussia and Germany; d) the theses about the borders of the German state, which allegedly has the right to reach where German speech sounds.

The above package of absurd assumptions for Polish intellectuals is complemented by criticism of the situation of religion in Nazism. The main message of Polish criticism in this area was summarised in the thesis: in view of the dreams of the power of the German nation, religious content must become secondary. Shortly before Hitler came to power, Father Stefan Wyszyński (later Primate of Poland) wrote about the religious chaos in Germany in Prad magazine and decided that it was created on purpose. He regretted that the German bishops are asking questions about fidelity: to whom do they owe it? To Christ or to the earthly homeland? Karol Koniński emphasised that one often hears that German religiosity begins where Christianity is dying

5 Ibidem, 157; Jan Rostworowski, “Nacjonalizm, jego uprawnienia i etyczne granice”, Przeglad Powszechny 157 (1923), 97-116.

6 Tochowicz, “Zasady wychowawcze nacjonalizmu..., 154-156.

7 Konstanty Michalski, Nieznanemu Bogu (Kraków: Koło Studiów Katolickich, 1936), 13-14. 
out. He regretted that the Germanic mythology, with its self-administration of its own race, wanted to remove crosses from rural roads as unworthy of the German cult of strength ${ }^{8}$. Polish critics of Nazism stressed that its vision in the German artists was anti-Christian: "in the place of the cross there would be a sign of the swastika, in the place of Christian love - honour and heroism; in the place of the universal Church there would be a new, German religion"9. This is no longer Christianity - it is pantheism, and it is more dangerous than atheism ${ }^{10}$.

The Nazi reform of sci e n ce also took part in building Nazism. In the opinion of Polish intellectuals it has primarily lost the sense of objective truth. In Poland, before 1939, it was written that German science had gone into the service of Nazism. A particularly questionable area of science was racial research supported by eugenics. The ideas that were behind Nazism were racism and racial research, then fashionable in Europe. Racism was considered to appear before National Socialism and very dangerous. Father Konstanty Michalski wrote about it in the following way: it is from "psychological anthropology, human race and blood that the myth is born in Germany in which the whole mission of the German nation is to be summarised"11. According to Konstanty Michalski, Karol Koniński, Stanisław Podoleński and others, Alfred Rosenberg played the most creative role in creating racism. It was written that in Der Mythus des $20 \mathrm{Jahr}$ (1930), Rosenberg created the myth of blood understood as the new German religion, the national faith. Its content was reduced to pseudo-scientific evidence that Aryan blood is what will overcome and replace the old Christian sacraments ${ }^{12}$. However, Rosenberg himself could not give this myth a messianic aura, as Ernst Krieck managed to do according to Polish critics. He brought to racism the messianism borrowed from the Slavs, while at the same time depriving it of its Christian character ${ }^{13}$.

Parallel to the criticism of racism there was a criticism of anti-Semi$\mathrm{t}$ is $\mathrm{m}$. The enormity of German anti-Semitism was incomprehensible in Poland. Attempts were made to indicate some of its moral or economic reasons, however in none of the Polish scientific journals did German anti-Semitism find any justification and all the reasons were considered inadequate to its scale. Antipolonis m was considered a permanent and constantly expanding element of Nazism - criticism of Nazism not only brings spectacular examples of it, but also reveals the mechanisms on which it was built: lies about Poles, unjustified claims to Polish lands, deception and frauds in current contacts.

8 Karol L. Koniński, "Logika swastyki”, Przegląd Powszechny 197 (1933), 305-306.

9 Michalski, Nieznanemu Bogu, 28.

10 Andrzej Niesiołowski, "Religia spólnoty narodowej. U źródeł narodowego socjalizmu”, Przegląd Powszechny 219 (1938), 10-24.

11 Michalski, Nieznanemu Bogu, 28.

12 Koniński, "Logika swastyki”.

13 Michalski, Nieznanemu Bogu, 28. 
The criticism of Nazism in the bibliography of sources published below was consistent and deep. Polish conservative, national and Catholic writings criticised the whole spectrum of ideas on which Nazism developed. This criticism speaks of the insignificant role of Adolf Hitler, it strongly exposes the fact that the Germans did not recognise their guilt for World War I. In the opinion of Polish critics, Nazism was not created by the agitated genius of Hitler, he only h e a d e d a "t e a m" ready for ruthless work in the name of Deutschland über Alles.

\section{Bibliography: The Polish Current of Criticism of Nazism before 1939}

1. “Biskupi niemieccy wobec Trzeciej Rzeszy”. Prąd 25 (1933), 63-75.

2. “Czy katolik może być hitlerowcem?”. Prąd 19 (1930), 268-270.

3. “J. Em. X Kard. Hlond o Niemczech, Polsce i Europie”. Prąd 22 (1932), 284-287.

4. “Kongregacja Seminariów i Uniwersytetów przeciw teoriom rasizmu”. Prąd 35 (1938), 267.

5. “Konkordat między Stolicą Apostolską a Rzecząpospolitą Niemiecką". Prąd 25 (1933), 241-264.

6. “Kościół Katolicki w Niemczech i hitleryzm”. Prąd 23-24 (1933), 272-283.

7. "Kształcenie nauczycieli szkół powszechnych w programie narodowo-socjalistycznym III-ciej Rzeszy”. Chowanna (1934), 138-139.

8. “Narodowo-socjalistyczny program Gotfryda Federa”. Prąd 25 (1933), 213-219.

9. “Potępienie książek hitlerowskich”. Prąd 26 (1934), 143.

10. “Spór polsko-niemiecki”. Prąd 37 (1939), 315-332.

11. “Sprawa Onckena”. Nowe Czasy, 19.03.1935.

12. "Sterylizacja w Niemczech". Prąd 25 (1933), 277-280.

13. “Szkolnictwo ogólnokształcące III-ciej Rzeszy”. Chowanna (1934), 138-139.

14. "Wzmożona walka z religią w sowietach". Prąd 27 (1934), 61.

15. “Zwycięstwo hitleryzmu”. Prąd 23-24 (1933), 181-188.

16. B. "Wyścig”. Myśl Narodowa 15 (1939), 220.

17. Bartoszewicz, Joachim. "Polska a Niemcy”. Myśl Narodowa 43 (1937), 653-654.

18. Bednarski, Stanisław, pr. "Międzynarodowy Kongres Wychowania Moralnego w Krakowie". Przegląd Powszechny 204 (1934), 130-136.

19. Błotnicki, Franciszek. “Chrześcijaństwo i antysemityzm”. Myśl Narodowa 9 (1937), 129-130.

20. Bobkowska, Wanda. "Reforma szkolna w Niemczech". Kultura $i$ Wychowanie 3 (1938), 173-201.

21. Bogdanowicz, Jan. "Właściwy sens totalizmu”. Myśl Narodowa 53 (1938), 813-814.

22. Borkowska, Alina. "Nędza i ucisk dzieci pod rządem bolszewickim”. Prąd 17 (1929), $245-253$.

23. Bruckus, Borys. "Narodowy socjalizm i los narodów nie-niemieckiej krwi", Przegląd Powszechny 193 (222), 68-77.

24. Bystroń, Jan St. Megalomania narodowa. Warszawa: Gebethner i Wolff, 1924.

25. Caro, Leopold. Kwestya żydowska w świetle etyki, ed. 2. Lwów: Jakubowski \& Zadurowicz, 1893.

26. Caro, Leopold. "Przewrót gospodarczy w III Rzeszy”. In: Leopold Caro, Antoni Żabko Potopowicz, Polityka gospodarcza III Rzeszy. Lwów: Polskie Towarzystwo Ekonomiczne we Lwowie, 1938.

27. Caro, Leopold. "Rasa a narodowość". Przegląd Powszechny 220 (1938), 182-191.

28. Chmaj, Ludwik. "Ernest Krieck i pedagogika polityczna”. Przegląd Powszechny 2013 (1937), $13-27$. 
29. Chojnacki, Piotr, pr. "Materializm dziejowy jako filozofia naukowego komunizmu". Ruch Katolicki 12 (1937), 543-553.

30. Czuj, Jan, pr. “Św. Augustyn a rasizm”. Ateneum Kapłańskie 44 (1939), 1-12.

31. Czuma, Ignacy. "Bolszewicka dialektyka moralności”. Prąd 18 (1930), 294-308.

32. Czuma, Ignacy. "Duchowe przygotowanie armii III Rzeszy (według opinii Hermana Rauschninga)”. Prąd 37 (1939), 333-346.

33. Czuma, Ignacy. Filozoficzne punkty styczne Zachodu i Bolszewizmu. Lublin: Drukarnia Mazowiecka, 1930.

34. Czuma, Ignacy. "Niemcy - naród bez młodzieży". In: Pod znakiem swastyki. Polscy prawnicy wobec Trzeciej Rzeszy 1933-1939. Wybór pism. Kraków: Ośrodek Myśli Politycznej, 2005.

35. Czuma, Ignacy. "Niemcy - naród bez młodzieży". Polska Zwrócona na Zachód 3 (1939), 2-26.

36. Czuma, Ignacy. “Spór polsko-niemiecki”. Prąd 37 (1939), 347-357.

37. Dąbrowski, S. ${ }^{14}$ Eugenika ze stanowiska katolickiego. Poznań: NIAK, 1938.

38. Dmowski, Roman. Polityka Polski i odbudowanie państwa, Vol. 1, ed. 3. Hanower, 1947.

39. Dobraczyński, Jan. "Fichte i Hegel ojcami Hitleryzmu”. Myśl Narodowa 12 (1939), 194.

40. Dr Zuzelski, pseud. (Stefan Wyszyński). “Z walk religijnych w Niemczech”. Ateneum Kapłańskie 21 (1935), 504-511.

41. Dutkowski, D. “Rasizm a Żydzi”. Myśl Narodowa 34 (1938), 527-529.

42. Dworak, Tadeusz. "O ocenę ducha i krwi”. Myśl Narodowa 16 (1939), 225-226.

43. Dworak, Tadeusz. “Totalne państwo narodowe”. Myśl Narodowa 47 (1937), 717-718.

44. Dyle, Alfred van. "Hitleryzm a religia”. Przeglad Powszechny 196 (1932), 31-47.

45. Frycz, Karol Stefan. "Na południe od Hitlera”. Myśl Narodowa 11 (1938), 154-155.

46. Frycz, Karol Stefan. "Traktat wersalski”. Myśl Narodowa (1934), 413-415.

47. Frycz, Karol Stefan. “Złe źródła faszyzmu i hitleryzmu”. Myśl Narodowa 18 (1939), 265-266.

48. Gajewski, K. Socjalizm wróg ludzkości. Kalisz: Wydawnictwo Tygodnika Narodowego „Ogniwo", 1938.

49. Gałęzowska, Irena. "Mit o jednostce zbiorowej”. Przegląd Powszechny 168 (1925), 263-291.

50. Giertych, Jędrzej. "Rasizm jako podwalina ideologiczna hitlerowskich Niemiec". Myśl Narodowa 30 (1934), 429-431.

51. Glass, Henryk. Ofensywa Komunizmu i drogi przeciwdziałania. Katowice: Księgarnia i Drukarnia Katolicka, 1938.

52. Gluziński, T. “Wobec nowych Niemiec”. Myśl Narodowa 9 (1933), 97-98.

53. Godlewski, F. “Etatyzm, socjalizm, komunizm”. Myśl Narodowa 43 (1938), 658-660.

54. Górski, Karol. Rodzina a kultura współczesna. Poznań: NIAK, 1935.

55. Górski, Karol. "Rodzina a współczesne prądy pedagogiczne”. Ruch Katolicki 5 (1935), 475-479.

56. Górski, Karol. Wychowanie personalistyczne. Poznań: NIAK, 1936.

57. Gralewski, Jan. "Prawdziwa Francja”. Myśl Narodowa 17 (1939), 241-244.

58. Granat, Wincenty, pr. "Zasady pedagogii katolickiej w świetle dogmatu odkupienia grzechu pierworodnego". Miesięcznik Katechetyczny i Wychowawczy 1-2 (1939), 26-27.

59. Grzelecki, S. "Führerprinzip". Myśl Narodowa (1936), 479-480.

60. Grzybowski, Konstanty. Dyktatura Prezydenta Rzeszy. Kraków: Gebethner i Wolff, 1934.

61. Grzybowski, Konstanty. Niemcy hitlerowskie. Kraków: Nakładem Szkoły Nauk Politycznych w Krakowie, 1934.

14 No surname, no name or only the author's initials means that the publication has been signed in this way and it is impossible to identify the author's full details. 
62. H.T. "Volk im Werden herausgegaben von Ernst Krieck. Leipzig, Armanen-Verlag. 2 Jahrgang, 1934. Vol. 1-5”. Kwartalnik Pedagogiczny 3-4 (1934), 311.

63. Hajewicz, J. “Problem polsko-niemiecki w wychowaniu”. Myśl Narodowa 34 (1930), 534-535; 35 (1930), 551-553.

64. Iwaszkiewiczowa, Zofia. "Główne idee Kongresu Wychowania Moralnego". Kwartalnik Pedagogiczny 1 (1935), 66-68.

65. J.K., “Współczesne prądy w wychowaniu”. Kwartalnik Pedagogiczny 1-2 (1938), 34-40.

66. Jasiński, Walery, pr. Światłocienie współczesnej pedagogiki. Poznań: NIAK - Biblioteczka Akcji Katolickiej nr 43, 1937.

67. Jastrzębska, Jadwiga. “Współczesne prądy w pedagogii niemieckiej”. Kwartalnik Pedagogiczny 3-4 (1933), 318-333.

68. Jaxa Bykowski, Ludwik. "Antropologja pedagogiczna w Polsce”. Kwartalnik Pedagogiczny 2 (1931), 135-140.

69. Jaxa-Bykowski, Ludwik. "Jeszcze o 'pacyfizmie’ w szkolnictwie niemieckim”. Myśl Narodowa 32 (1930), 496-498; 33 (1930), 518-519.

70. Jeżowa, Kazimiera. “Agitacja antypolska w geografii niemieckiej”. Rocznik Gdański II, III (1928/1929).

71. Junius, "Poglądy społeczne Adolfa Hitlera”. Kultura i Wychowanie 4 (1938), 304-318.

72. Kaczmarek, L. "Na froncie walki z rasizmem”. Ateneum Kapłańskie 35 (1935).

73. Kijas, Juliusz. "Realizacja zasad narodowego socjalizmu w szkolnictwie niemieckim ( $\mathrm{Z}$ wycieczki pedagogicznej do Niemiec)”. Muzeum 2 (1938), 87-94.

74. Kliszewicz, Adolf. “Totalizm współczesny”. Ateneum Kapłańskie 44 (1939), 13-30.

75. Komarnicki, Wacław. “Totalizm a Polska”. Myśl Narodowa 49 (1937), 751-752.

76. Koneczny, Feliks. “Bizantynizm niemiecki”. Przegląd Powszechny 176 (1927), 18-45.

77. Koneczny, Feliks. Cywilizacja żydowska. Warszawa: Wydawnictwo „Antyk”, 2001.

78. Koneczny, Feliks. “Dwoistość Niemiec”. Myśl Narodowa 53 (1930), 799-800.

79. Koneczny, Feliks. Kośció jako polityczny wychowawca narodów. Warszawa: Biblioteka Akcji Katolickiej nr 15, 1938.

80. Koneczny, Feliks. "Państwo a metody życia zbiorowego". Myśl Narodowa 39 (1930), 605-607.

81. Koneczny, Feliks. "Prawda a cywilizacje”. Myśl Narodowa 4 (1937), 49-50; 5 (1937), 67-68.

82. Koneczny, Feliks. "Rasa a cywilizacja”. Tęcza 32-33 (1929), 1-3.

83. Koniński, Karol Ludwik. "Logika swastyki”. Przegląd Powszechny 197 (1933), 304-326.

84. Kordacz, Franciszek, bpp. “O liberalizmie, kapitalizmie i socjalizmie”. Prąd 20 (1931), 322.

85. Kościelecki, Władysław. "Pius XI wobec prądów religijnych w III Rzeszy”. Ateneum Kapłańskie 40 (1937).

86. Kozicki, Stanisław. “Chaos niemiecki”. Myśl Narodowa 55 (1932), 797-798.

87. Kozicki, Stanisław. “Faszyzm a Żydzi”. Myśl Narodowa 53 (1934), 431-433.

88. Kozicki, Stanisław. “Jasna sytuacja”. Myśl Narodowa 20 (1939), 289-290.

89. Kozicki, Stanisław. "Nacjonalizm niemiecki. Z powodu książki Alfreda Rosenberga Der Mythus des 20 Jahrhunderts". Myśl Narodowa 33 (1932), 24-25.

90. Kozicki, Stanisław. "Niemcy a Polska”. Myśl Narodowa 54 (1930), 813-815.

91. Kozicki, Stanisław. “Polityka Niemiec”. Myśl Narodowa 53 (1934), 781-782.

92. Kozicki, Stanisław. "Polska, Niemcy i Paneuropa”. Myśl Narodowa 22 (1930), 337-339.

93. Kozicki, Stanisław. “Traktat Wersalski”. Myśl Narodowa 29 (1934), 413-414.

94. Kozłowiecki, Adam, bpp. Ucisk i strapienie. Kraków: Wydawnictwo WAM, 1995.

95. Krotoski, Karol. "Spowiedź publiczna Kanclerza Niemiec”. Przegląd Powszechny 203 (1934), $46-65$. 
96. Krzyżanowski, Adam. Bolszewizm. Kraków: Nakładem Księgarni S.A. Krzyżanowskiego, 1920.

97. Kuchta, Jan. Nowe kierunki i dążenia we współczesnej katolickiej pedagogice. Lwów: Księgarnia Schweitzera, 1939.

98. L.B. “Internationale Zeitschrift für Erziehungswissenschaft, 1933/34”. Kwartalnik Pedagogiczny 2 (1934), 190-191.

99. M. “Zygmunta Nowakowskiego 'Niemcy à la minute' (Gebethner i Wolf, 1933)”. Myśl Narodowa 29 (1933), 425.

100. MAF. “Niemcy o Dmowskim”. Myśl Narodowa 30 (1936), 461-465.

101. Manteuffel, Marjan. “Głębsze przyczyny tzw. 'kryzysu światowego”'. Prąd 23 (1932), 3-15.

102. Marchwiński, A. “Doraźne cele hitleryzmu”. Myśl Narodowa 26 (1932), 371-372.

103. Michalski, Konstanty, pr. “Dzień ognia”. In: Konstanty Michalski, Nieznanemu Bogu. Kraków: Koło Studiów Katolickich i Naukowy Instytut Katolicki, 1936.

104. Michalski, Konstanty, pr. “Fermenty religijne w Trzeciej Rzeszy”. Przegląd Powszechny 201 (1934), 347-367.

105. Michalski, Konstanty, pr. Gasnące blaski. Kraków: Biblioteczka „Czasu”, 1934.

106. Michalski, Konstanty, pr. Kościół wobec narodowego socjalizmu. Kraków: Biblioteczka „Czasu”, 1934.

107. Michalski, Konstanty, pr. "Nieznanemu Bogu”. In: Konstanty Michalski. Nieznanemu Bogu. Kraków: Koło Studiów Katolickich i Naukowy Instytut Katolicki, 1936.

108. Michalski, Konstanty, pr. "Resurectio et Vita". In: Konstanty Michalski. Nieznanemu Bogu. Kraków: Koło Studiów Katolickich i Naukowy Instytut Katolicki, 1936.

109. Michalski, Konstanty, pr. “Tomizm wobec współczesnej filozofii dziejów”. In: Księga Pamiątkowa Międzynarodowego Kongresu Filozofii Tomistycznej w Poznaniu 1934 rok. „Studia Gnesnensia”, Vol. XII, Gniezno 1935, 1-29.

110. Michalski, Konstanty, pr. “Trzy mity”. In: Konstanty Michalski. Nieznanemu Bogu. Kraków: Koło Studiów Katolickich i Naukowy Instytut Katolicki, 1936.

111. Michalski, Konstanty, pr. “Zagadnienia filozofii współczesnej”. Przegląd Współczesny 115 (1931).

112. Morawski, K.M. “Hitleryzm a katolicyzm”. Myśl Narodowa 34 (1932), 493-495.

113. Moskała, Romuald SJ. "Nasz sąsiad wschodni (Szkic o bolszewizmie)”, cz. I, II. Przegląd Powszechny 145 (1920), 376-388; 146 (1920), 33-47.

114. Mysłakowski, Zygmunt. Totalizm czy kultura. Kraków: Spółdzielnia Wydawnicza „Czytelnik”, 1938.

115. Niesiołowski, Andrzej. “Czy totalizm jest koniecznością historyczną?”. Przegląd Powszechny 2015 (1937), 82-95.

116. Niesiołowski, Andrzej. Formy i metody pracy oświatowej. Próba klasyfikacji i analizy socjologicznej, z Przedmowa L. Jaxy Bykowskiego. Warszawa: „Księgarnia Polska” Towarzystwa Macierzy Szkolnej, 1932.

117. Niesiołowski, Andrzej. "Kryzys kultury niemieckiej a Polska”. Przegląd Katolicki 13 (1937), 203-207.

118. Niesiołowski, Andrzej. O ideologjach polityczno-społecznych. Poznań: Drukarnia św. Wojciecha, 1935.

119. Niesiołowski, Andrzej. "Perspektywy totalizmu”. Przegląd Powszechny 2015 (1937), 204-2014.

120. Niesiołowski, Andrzej. "Religia spólnoty narodowej. U źródeł narodowego socjalizmu”. Przegląd Powszechny 219 (1938), 10-24.

121. Niesiołowski, Andrzej. Zarys pedagogiki ogólnej. Rękopisy z oflagu, ed. Janina Kostkiewicz. Kraków: Wydawnictwo Uniwersytetu Jagiellońskiego, 2017.

122. Niesiołowski, Andrzej. “Zmierzch materializmu”. Przegląd Powszechny 218 (1938), 14-30. 
123. Nowaczyński, Adolf. "Swastyka”. Myśl Narodowa 5 (1932), 69-71.

124. Pastuszka, Józef, pr. Filozofia współczesna, t. 1. Warszawa: Gebethner i Wolff, 1934.

125. Pastuszka, Józef, pr. Filozofia współczesna, t. 2. Lublin: TN KUL, 1936.

126. Pastuszka, Józef, pr. "Filozoficzne i społeczne idee A. Hitlera (Rasizm)”. Ateneum Kapłańskie 40 (1937), 329-344; 441-453.

127. Pastuszka, Józef, pr. "Filozoficzne i społeczne idee A. Hitlera (Rasizm)”. Ateneum Kapłańskie 41 (1) (1938), 23-37.

128. Pastuszka, Józef, pr. Filozoficzne i społeczne idee A. Hitlera (Rasizm). Lublin: Towarzystwo Wiedzy Chrześcijańskiej - Uniwersytet, 1938.

129. Pastuszka, Józef, pr. “Filozoficzne podstawy rasizmu”. Ruch Katolicki 4 (1939), 156-172.

130. Pastuszka, Józef, pr. "Irracjonalizm w najnowszej filozofii”. Ateneum Kapłańskie 1 (1934).

131. Pastuszka, Józef, pr. “Krytyka światopoglądu rasistowskiego”. Ruch Katolicki 7 (1939), 305-321.

132. Pastuszka, Józef, pr. "Nacjonalizm a katolicyzm. Opinie biskupów, uczonych, polityków i publicystów”. Ateneum Kapłańskie 20 (1927), 88-89.

133. Pastuszka, Józef, pr. "Nacjonalizm a religia”. Prąd 11-12 (1926), 499-510.

134. Pastuszka, Józef, pr. "Prądy materjalistyczne w filozofii współczesnej”. Ateneum Kapłańskie 32 (1933), 13-38.

135. Pastuszka, Józef, pr. “Psychoanaliza”. Ateneum Kapłańskie 31 (1933), 105-121.

136. Pastuszka, Józef, pr. “Rasizm jako światopogląd”. Ruch Katolicki 9 (1939), 1-12; 101-116.

137. Pastuszka, Józef, pr. "Współczesne prądy filozoficzne”. Kultura i Wychowanie 3 (1938), 202-217.

138. Pastuszka, Józef, pr. Z filozofii i psychologii komunizmu. Lublin: Uniwersytet Lubelski, 1938.

139. Piestrzyński, R. "Państwo absolutystyczne i jego zwyrodnienie". Myśl Narodowa 13 (1933), 161-163.

140. Podoleński, Stanisław, pr. “Antyreligijny front socjalnej demokracji w Austrii”. Przegląd Powszechny 186 (1930), 374-379.

141. Podoleński, Stanisław, pr. "Biała rasa w niebezpieczeństwie”. Przegląd Powszechny 217 (1938), $32-41 ; 418-421$.

142. Podoleński, Stanisław, pr. "Etyka katolicka i eugenika i medycyna”. Przegląd Powszechny 214 (1937), 195-208.

143. Podoleński, Stanisław, pr. "Eugenika dzisiejsza, jej drogi i bezdroża”. Przegląd Powszechny 193 (1932), 319-331; 194 (1932), 166-186.

144. Podoleński, Stanisław, pr. "Eugenika i ruch eugeniczny”. Przegląd Powszechny 193 (1932), 318-331.

145. Podoleński, Stanisław, pr. “Herman Muckermann: Gestaltung der Lebenslage. XVI Aufl.”. Przegląd Powszechny 203 (1934).

146. Podoleński, Stanisław, pr. “Jak socjalizm wychowuje lud?”. Przegląd Powszechny 149/150 (1921), 93-109.

147. Podoleński, Stanisław, pr. "Polskie Towarzystwo Eugeniczne”. Przegląd Powszechny 200 (1933), $48-56$.

148. Podoleński, Stanisław, pr. “Problem lekarskich porad i świadczeń przedślubnych”. Przegląd Powszechny 204 (1934), 45-63.

149. Podoleński, Stanisław, pr. "Projekt polskiej Ustawy Eugenicznej”. Przegląd Powszechny 204 (1934), 387-393.

150. Podoleński, Stanisław, pr. “Stowarzyszenie Chrześcijańsko-Narodowego Nauczycielstwa Szkół Powszechnych”. Przegląd Powszechny 177 (1928), 242-245. 
151. Podoleński, Stanisław, pr. "Ustawa sterylizacyjna w Niemczech". Przegląd Powszechny 201 (1934), 46-67.

152. Podoleński, Stanisław, pr. "Wychowawczo-oświatowa akcja socjalizmu w Polsce”. Przegląd Powszechny 177 (1928), 282-305.

153. Podoleński, Stanisław, pr. "VI Międzynarodowy Kongres Wychowania Moralnego". Przegląd Powszechny 172 (1926), 373-376.

154. "Podstawy wychowania narodowo-socjalistycznego w III-ciej Rzeszy, Dział: Współczesny Ruch Pedagogiczny”. Chowanna (1934/1935), 137-138.

155. Poszwa, Alojzy, pr. "Dążenia eugeników polskich w świetle katolickich zasad moralnych". Ateneum Kapłańskie 30 (1932), 433-445.

156. Poszwa, Alojzy, pr. Eugenika w Polsce. Płock: Wydawnictwo DIAK, 1938.

157. Quis. “Co się dzieje wśród Żydów”. Myśl Narodowa 15 (1938), 207.

158. Quis. “Zaborczość niemiecka”. Myśl Narodowa 21 (1938), 334-335.

159. R. “Chaos niemiecki”. Prad 23 (1932), 184-185.

160. Rembaliński, Jan. “Dwie tendencje nacjonalizmu niemieckiego”. Myśl Narodowa 10 (1932), 122.

161. Rembaliński, Jan. “Hitler - 'mąż pokoju'?”. Myśl Narodowa 10 (1932), 121.

162. Romahn, Edmund. "Ideologiczne podłoże narodowego socjalizmu na tle literatury o kulturze". Kultura i Wychowanie 5 (1938), 128-147.

163. Rostworowski, Jan, pr. "Nacjonalizm, jego uprawnienia i etyczne granice”. Przegląd Powszechny 157 (1923), 97-116.

164. Rybarski, Roman. “Odmiany nacjonalizmu”. Myśl Narodowa 47 (1938), 717-719.

165. Rybarski, Roman. "Wewnętrzna niezależność gospodarcza. Sprawa żydowska”. Myśl Narodowa 1 (1937), 3-6.

166. Rymar, Stanisław. "Wyjątkowa chwila”. Myśl Narodowa 27 (1937), 413-415.

167. Ryniewicz, A. "Przewartościowanie dawnych wartości w szkolnictwie niemieckim”. Przegląd Pedagogiczny 17 (1936).

168. Ryx, Jerzy. "Błędy rasizmu”. Prąd 35 (1938), 339-349.

169. S.M. "Adolf Hitler i jego program". Przeglad Powszechny 196 (1932), 3-30.

170. Sawicki, Franciszek, pr. "Nowoczesne teorie rasowe”. Przegląd Powszechny 201 (1934), 19-33.

171. Sawicki, Franciszek, pr. Rasa i światopogląd. Warszawa: Wydawnictwo Studium Filozoficzno-Religijnego, 1939.

172. Sawicki, Franciszek, pr. "Wiara i filozofia współczesna”. In: Księga pamiątkowa ku uczczeniu dziesięciolecia biskupstwa J.E. Księdza biskupa dr-a Stanisława W. Okoniewskiego biskupa chełmińskiego. Pelplin: Seminarium Duchowne, 1936.

173. Sekreta, Mirosław. "Polityka szkolna Niemiec hitlerowskich". Chowanna (1935).

174. Sekreta, Mirosław. "Współczesna niemiecka filozofia i pedagogika kultury”. Kultura i Wychowanie 3 (1935/1936), 236-253.

175. Skaliński, J. „Najnowsza «ewangelia» bolszewizmu”. Przegląd Powszechny 221 (1939), 289-310.

176. Sośnicki, Kazimierz. "Kierunek polityczny państwa a organizacja szkolnictwa”. Kwartalnik Pedagogiczny 3-4 (1934), 201-220.

177. Stepa, Jan, pr. Komunizm a światopogląd katolicki. Poznań: NIAK, 1937.

178. Stepa, Jan, pr. U źródeł niemieckiego totalizmu. Poznań: Archidiecezjalny Instytut Akcji Katolickiej, 1938.

179. Stojanowski, Karol. “Eugenika”. Wychowanie Fizyczne 1 (1927).

180. Stojanowski, Karol. “Myśl rasowa w Szwecji”. Myśl Narodowa 20 (1932), 274-275.

181. Stojanowski, Karol. “Niemiecka rasa”. Myśl Narodowa 36 (1935), 542-545. 
182. Stojanowski, Karol. "Niemiecka rasa”. Założenia doktryny rasowej nordycznej a niemieckiej. Toruń: Drukarnia S. Buszczyńskiego, 1935.

183. Stojanowski, Karol. “Niemieckie prawo chłopskie”. Myśl Narodowa 1 (1934), 2-5.

184. Stojanowski, Karol. Polsko-niemieckie zagadnienia rasy. Katowice: Księgarnia i Drukarnia Katolicka S.A., 1939.

185. Stojanowski, Karol. “Prężność nordyzmu”. Myśl Narodowa 32 (1931), 11-12.

186. Stojanowski, Karol. Przyczynki do zróżnicowania rasowego młodzieży polskiej. Warszawa: Drukarnia "Lech", 1925.

187. Stojanowski, Karol. Rasizm przeciw Słowiańszczyźnie. Poznań: Głos, 1934.

188. Stojanowski, Karol. Rasowe podstawy eugeniki. Karczówka k. Kielc-Poznań: Drukarnia św. Józefa, 1927.

189. Stojanowski, Karol. Rassenlehre gegen Slawentum. Berlin: Dahlem Publikationsstelle, 1935.

190. Stojanowski, Karol. Stan i zadania badań antropologicznych nad Wielkopolską. Poznań: Druk. św. Wojciecha, 1929.

191. Stojanowski, Karol. Z badań nad antropologia Śląska. Skład rasowy katowickiej młodzieży poborowej. Katowice: Wydawnictwo Instytutu Śląskiego - Polski Śląsk, 1937.

192. Stroński, S. “Załamania w Gdańsku”. Myśl Narodowa 14 (1932), 177-178.

193. Studnicki, Władysław. Wobec nadchodzącej drugiej wojny światowej. Warszawa: by the Author, 1939.

194. Suchodolski, Bogdan. "O trzech krańcowych kierunkach wychowawczych”. Ruch Pedagogiczny $4(1947 / 1948)$.

195. Szczutowski, Stanisław. “Paneuropa i 'trzy B”'. Myśl Narodowa 35 (1930), 541-543.

196. Szlagowski, Antoni, pr. “O położeniu Kościoła w Trzeciej Rzeszy”. Myśl Narodowa 22 (1938), 339-341.

197. Szymański, Antoni, pr. "Bezskuteczność statolatryzmu i nacjonalizmu”. Prąd 23 (1932), 203-210.

198. Szymański, Antoni, pr. Bolszewizm. Poznań: Księgarnia św. Wojciecha, 1929.

199. Szymański, Antoni, pr. “Chaos niemiecki”. Prąd 23 (1932), 182-185.

200. Śliwińska-Zarzecka, Maria. "VI-ty Międzynarodowy Kongres Wychowania Moralnego". Miesięcznik Katechetyczny i Wychowawczy 6-7 (1934), 290-293.

201. Śniehota, Franciszek. "Zeitschrieft für pädagogische Psychologie, experimentelle Pädagogik und jugendkundliche Forschung. 34 Jahrg. Nr. 1-6. Leipzig 1933”. Kwartalnik Pedagogiczny 4 (1934), 345-351.

202. Śniehota, Franciszek. "Zeitschrieft für pädagogische Psychologie und Jugendkunde. Leipzig, 34. Jahrg., 1933, Nr 7-12”. Kwartalnik Pedagogiczny 2 (1934), 191-199.

203. Świerzowicz, Jan. “Tragedia religijna Niemiec”. Myśl Narodowa 20 (1938), 306-308.

204. Święcicki, J.M. “Na marginesie problemu koedukacji”. Przegląd Powszechny 206 (1935).

205. Świrski, Ignacy, pr. "Eugenika a moralność”. Ateneum Kapłańskie 32 (1933), 433-434.

206. Tabaczyński, S. "Faktorie niemieckiego imperializmu”. Myśl Narodowa 20 (1938), 305-306.

207. Taczanowski, Czesław. "Odwieczne oblicze dzisiejszej polityki niemieckiej”. Myśl Narodowa 41 (1938), 51-52.

208. Tochowicz, Paweł, pr. "Niemiecki Rembrandt - J. Langbehn”. Ateneum Kapłańskie 40 (1937), 478-482.

209. Tochowicz, Pawel, pr. "Zasady wychowawcze nacjonalizmu i politycyzmu (pp. I)". Ateneum Kapłańskie 39 (1937), 151-159; 250-263.

210. Tochowicz, Paweł, pr. "Zasady wychowawcze nacjonalizmu i politycyzmu (pp. II)”. Ateneum Kapłańskie 40 (1937), 367-378. 
211. Turowski, Konstanty. “Z życia młodzieży akademickiej”. Prąd 22 (1932), 341-342.

212. Urban, Jan, pr. "Bolszewicy wobec religii w Rosji, na Węgrzech i w Bawarii. Stosunek państwa do Kościoła w przyszłej konstytucji niemieckiej”. Przegląd Powszechny 141-142 (1919), 389-394.

213. Urban, Jan, pr. “Czy socjalizm można pogodzić z katolicyzmem”. Przegląd Powszechny 169 (1926), 3-20; 164-172.

214. Urban, Jan, pr. "Nacjonalizm katolicki a nacjonalizm wszechpolski”. Przegląd Powszechny 162 (1924), 193-205.

215. Urban, Jan, pr. "Nasz stosunek do socjalizmu”. Przegląd Powszechny 174 (1927), 145-161; 314-340.

216. Urban, Jan, pr. “Socjalizm jako religia”. Przegląd Powszechny 151-152 (1921), 5-23.

217. Wachowski, Marian. "Ernst Krieck, Nationalpolitische Erziehung, ed. 4, Leipzig, Armanen-Verlag, 1934, ppp. IV + 186”. Kwartalnik Pedagogiczny 3-4 (1934), 302-306.

218. Walczyński, R. Franciszek. “Apoteoza rasy kosztem historii”. Przegląd Powszechny 220 (1938), 3-14.

219. Walczyński, R. Franciszek. "Hitler w terminie (U źródeł dyktatury)”. Przeglad Powszechny 223 (1939), 47-63.

220. Walczyński, R. Franciszek. “Mit XX wieku”. Przegląd Powszechny 219 (1938), 202-211.

221. Wasilewski, Zygmunt. "Parę słów o nacjonalizmie polskim". Myśl Narodowa 43 (1938), 662-663.

222. Wasilewski, Zygmunt. "Stosunek do Żydów dziś i 50 lat temu”. Myśl Narodowa 24 (1934), 361-362.

223. Wasiutyński, Wojciech. “Tragedia Niemiec”. Myśl Narodowa 41 (1933), 607-608.

224. Werbel, Kazimierz, pr. "Die Pädagogik der nichtchristlichen Kulturvölker, Herausgegeben von Josef Schröteler und Mitarbeit von J.B. Aufhauser, H. Brunnengräber [u.andere], München 1934". Kwartalnik Pedagogiczny 2-3 (1935), 157-158.

225. Werbel, Kazimierz, pr. "Handbuch der Erziehungswissenschaft. Herausgegeben im Auftrag des Deutschen Instituts für wissenschaftliche Pädagogik - Münster i. W. von Fr. X. Egersdorfer, M. Ettlinger, G. Raederscheidt, J. Schröteler. München, Kösel u. Fr. Pustet”. Kwartalnik Pedagogiczny 2-3 (1935), 155-157.

226. Weryński, Henryk, pr. "Bezdroża wychowania”. Ruch Katolicki 6 (1936), 414-423.

227. Weryński, Henryk, pr. "Kościół katolicki wobec przemian fizjonomii Europy”. Ruch Katolicki 4 (1934), 9-14.

228. Weryński, Henryk, pr. "Laicyzm w swym rozwoju historycznym". Ruch Katolicki (1931), 369-375.

229. Weryński, Henryk, pr. “Międzynarodowy Kongres Wychowania Moralnego”. Miesięcznik Katechetyczny $i$ Wychowawczy 1934, 394.

230. Wicher, Władysław, pr., "Świadome macierzyństwo (eugenika, rasizm, aborcja)". Ateneum Kapłańskie 34 (1934), 479-489.

231. Wiśniewski, M. "Przyczyny antysemityzmu w Niemczech”. Myśl Narodowa 18 (1933), $243-$ 244; 19 (1933), 259-262; 20 (1933), 275-276.

232. Wojtyński, W. “Zjazdy oświatowe i kongresy pedagogiczne w okresie międzywojennym”. Przegląd Historyczno-Oświatowy 2[6] (1959), 20-21.

233. Wolański, Edward. "Hitleryzm w niemieckiej prasie pedagogicznej”. Muzeum 1 (1934), 46-50.

234. Wóycicki, Aleksander, pr. "Podstawy wychowania moralnego". In: Sity moralne wspólne wszystkim ludziom, ich źródła i rozwój przez wychowanie. Kraków: Komitet Organizacyjny VI-go Międzynarodowego Kongresu Wychowania Moralnego, 1934, 284-298. 
235. Wóycicki, Aleksander, pr. "Rola wychowania w naprawie niesprawiedliwości społecznej”. In: Katolicka myśl wychowawcza. Pamiętnik II Studium Katolickiego w Wilnie w dn. 28.VIII-1. IX.1936r. Poznań: Naczelny Instytut Akcji Katolickiej, 1937.

236. Wóycicki, Aleksander, pr. Socjalizm a religia. Studjum socjologiczne. Poznań-Warszawa: Nakładem Księgarni św. Wojciecha, 1918.

237. X.F.G., Socyalizm jego historya i zasady. Warszawa: Nakładem Drukarni Ludowej.

238. Z.M. "Ernst Krieck. Wychowanie narodowo-polityczne, przeł. O. Wawrzkowicz. Wstęp napisał dr Antoni Ryniewicz. Bibl. Prz. Dz. Ped. T. 32 pod red. Dr. Zygmunta Ziembińskiego. Książnica - Atlas, Lwów-Warszawa, str. 269”. Kwartalnik Pedagogiczny 1-2 (1937), 61-63.

239. Z.P.P., "Agitacja antypolska w geografii niemieckiej”. Myśl Narodowa 19 (1930), 229-300; 20 (1930), 314-316.

240. Zajdlicz, A., pseud. (Andrzej Niesiołowski). "Kryzys kultury niemieckiej a Polska”. Przegląd Katolicki 13 (1937), 203-204.

241. Zajdlicz, Aleksander, pseud. (Andrzej Niesiołowski). "Próba ogniowa protestantyzmu”. Przegląd Katolicki 20 (1937), 324.

242. Zieliński, Stanisław. "Hitler (odczyt wygłoszony 12 czerwca w Sali Sokoła w Tarnopolu)". Myśl Narodowa 32 (1932), 464-466.

243. Ziembiński, Zenon. "Lexikon der Pädagogik der Gegenwart Her vom Deutschen Institut für wissenschaftliche Pädagogik, Münster in Wsetphalen. Redaktor: Dr. Josef Spieler, 2 tomy, Freiburg i/Br., Herder u. Co, 1930, str. XVI+szpp. 1344 i str. XVI+szpp. 1498”. Kwartalnik Pedagogiczny 3-4 (1934), 293-294. 